\title{
Impaired associative taste learning and abnormal brain activation in kinase-defective eEF2K mice
}

\author{
Iness Gildish, ${ }^{1,5}$ David Manor, ${ }^{1,5}$ Orit David, ${ }^{1}$ Vijendra Sharma, ${ }^{1}$ David Williams, ${ }^{2}$ \\ Usha Agarwala, ${ }^{3}$ Xuemin Wang, ${ }^{3}$ Justin W. Kenney, ${ }^{3}$ Chris G. Proud, ${ }^{2,3}$ and \\ Kobi Rosenblum ${ }^{1,4,6}$
}

${ }^{1}$ Department of Neurobiology, University of Haifa, Haifa 31905, Israel; ${ }^{2}$ College of Life Sciences, University of Dundee, Dundee DD1 $5 H N$, United Kingdom; ${ }^{3}$ School of Biological Sciences, Life Sciences Building, University of Southampton, Southampton SO17 1 BJ, United Kingdom; ${ }^{4}$ Center for Gene Manipulation in the Brain, University of Haifa, Haifa 31905, Israel

\begin{abstract}
Memory consolidation is defined temporally based on pharmacological interventions such as inhibitors of mRNA translation (molecular consolidation) or post-acquisition deactivation of specific brain regions (systems level consolidation). However, the relationship between molecular and systems consolidation are poorly understood. Molecular consolidation mechanisms involved in translation initiation and elongation have previously been studied in the cortex using taste-learning paradigms. For example, the levels of phosphorylation of eukaryotic elongation factor 2 (eEF2) were found to be correlated with taste learning in the gustatory cortex (GC), minutes following learning. In order to isolate the role of the eEF2 phosphorylation state at Thr-56 in both molecular and system consolidation, we analyzed cortical-dependent taste learning in eEF2K (the only known kinase for eEF2) ki mice, which exhibit reduced levels of eEF2 phosphorylation but normal levels of eEF2 and eEF2K. These mice exhibit clear attenuation of cortical-dependent associative, but not of incidental, taste learning. In order to gain a better understanding of the underlying mechanisms, we compared brain activity as measured by MEMRI (manganese-enhanced magnetic resonance imaging) between eEF2K ki mice and WT mice during conditioned taste aversion (CTA) learning and observed clear differences between the two but saw no differences under basal conditions. Our results demonstrate that adequate levels of phosphorylation of eEF2 are essential for cortical-dependent associative learning and suggest that malfunction of memory processing at the systems level underlies this associative memory impairment.
\end{abstract}

Different learning paradigms subserved by different brain structures in different species have a common temporal axis with three clear stages: acquisition, consolidation, and retrieval (Abel and Lattal 2001). Additional stages may be involved if the extraction of information from the memory store during the retrieval phase involves relearning and reconsolidation (Bailey et al. 1996; Debiec et al. 2002). Memory consolidation, as a component of the learning process, is divisible into different forms based on distinct spatio-temporal characteristics. Molecular memory consolidation refers to an initial stage of memory formation that is labile and sensitive to inhibitors of protein synthesis (Rosenblum et al. 1993). Whereas systems consolidation relates to transfer of information from one brain area to another and is characterized by larger scales in both time (days, weeks) and space (millimeters, centimeters), eventually the whole consolidation process induces a new, long-lasting pattern of behavior that is not easily extinguished (Alberini 2005). However, the relationships between these two forms of consolidation are not clear (Dudai 2004). In the last decade, various researchers have extended our knowledge of molecular consolidation by measuring and analyzing the regulation of the translation machinery itself, for example, in the gustatory cortex (GC) following novel taste learning (Costa-Mattioli et al. 2007; Elkobi et al. 2008; Belelovsky et al. 2009).

\footnotetext{
${ }^{5}$ These authors contributed equally to this work.

${ }^{6}$ Corresponding author.

E-mail kobir@psy.haifa.ac.il.

Article is online at http://www.learnmem.org/cgi/doi/10.1101/Im.023937.111.
}

Protein synthesis, the last step in gene expression and a key control process for its regulation, can be divided into initiation, elongation, and termination (Sonenberg et al. 2000; Richter and Klann 2009). The process of elongation, like initiation, requires nonribosomal proteins, termed eukaryotic elongation factors (eEFs). The translocation of peptidyl-tRNA from the ribosomal A-site to the P-site is mediated by eEF2 and coupled to GTP hydrolysis (Proud 2000). Phosphorylation on Thr-56 by its specific calcium ion $\left(\mathrm{Ca}^{2+}\right)$-dependent kinase, elongation factor 2 kinase (eEF2K, also known as CaMKIII) inhibits eEF2 activity (Marin et al. 1997). The inhibition is probably mediated by impairment of the interaction of eEF2 with the ribosome (Carlberg et al. 1990; Redpath and Proud 1993). In neurons, activation of NMDA and group-1 mGluR receptors induces eEF2 phosphorylation and attenuates general translation (Scheetz et al. 2000; Park et al. 2008). Phosphorylation of eEF2 on Thr56 by its specific kinase, eEF2K, was increased in the GC following novel taste learning (Belelovsky et al. 2005, 2007); however, it is not clear whether this phosphorylation has a system-level effect and whether it affects different types of taste learning.

The aim of the present study was to test the direct effects of manipulating eEF2 phosphorylation and, thus, eEF2 activity, on cortical-dependent learning and memory as well as its effect on brain activity at the systems level. To this end, we analyzed behavior (i.e., negative and positive forms of taste learning and memory), biochemistry at the protein level, and functional neuroanatomy by means of manganese-enhanced magnetic resonance imaging (MEMRI), in genetically engineered eEF2K $k i$ (i.e., kinase-dead eEF2K) mice. Our results demonstrate that reducing levels of brain eEF2 phosphorylation in mice by genetic manipulation of eEF2K 
specifically impaired cortical-dependent associative, but not incidental, taste learning, and we suggest that abnormality on the systems level underlies this cognitive impairment.

\section{Materials and Methods}

\section{Subjects}

The mice contained a knock-in ( $k i$ ) mutation in eukaryotic elongation factor 2 kinase (eEF2K). The residue Asp273 in the catalytic domain of eEF2K was converted to alanine (D273A) (Fig. 1A). As a result of the knock-in mutation D273A, a mutant of eEF2K that displays drastically decreased catalytic activity (see Results) was obtained, and the phosphorylation of eukaryotic elongation factor 2 (eEF2) was greatly reduced in these mice. eEF2K itself was expressed normally, and the main effect was on the phosphorylation of eEF2. The eEF2K[D273A] knock-in mice were generated at the Center for Functional Genomics (SUNY-Albany, NY).

Mice were genotyped, and three lines were established from the heterozygote founders: wild-type (eEF2K WT), D273A homozygote (eEF2K ki), and heterozygote mice. For behavioral and biochemical tests, adult male mice weighing 20-26 g (age 2-4 mo) were used. Mice were maintained on a 12/12-h light/dark cycle. The procedures were performed in strict accordance with the University of Haifa regulations and the E.U. and US National Institute of Health guidelines.

\section{Behavioral procedures}

\section{Conditioned taste aversion}

In all experiments described, the comparison is between $k i$ and WT littermates. Conditioned taste aversion (CTA) was performed according to Costa-Mattioli et al. (2007). Saccharin $(0.5 \% \mathrm{w} / \mathrm{v}$, sodium salt; CS Chemicals) was used as the novel taste in training, i.e., the conditioned stimulus (CS), and i.p.-injected $(0.14 \mathrm{mM}$ $\mathrm{LiCl}$; Sigma) at $2 \%$ of body weight was the malaise-inducing agent, i.e., unconditioned stimulus (UCS). At the beginning of the behavioral experiment, the mice were trained for $3 \mathrm{~d}$ to drink from pipettes during 20-min periods; they received two pipettes, each containing $5 \mathrm{~mL}$ of water. On the conditioning day (day 4), the mice were allowed to drink the saccharin solution instead

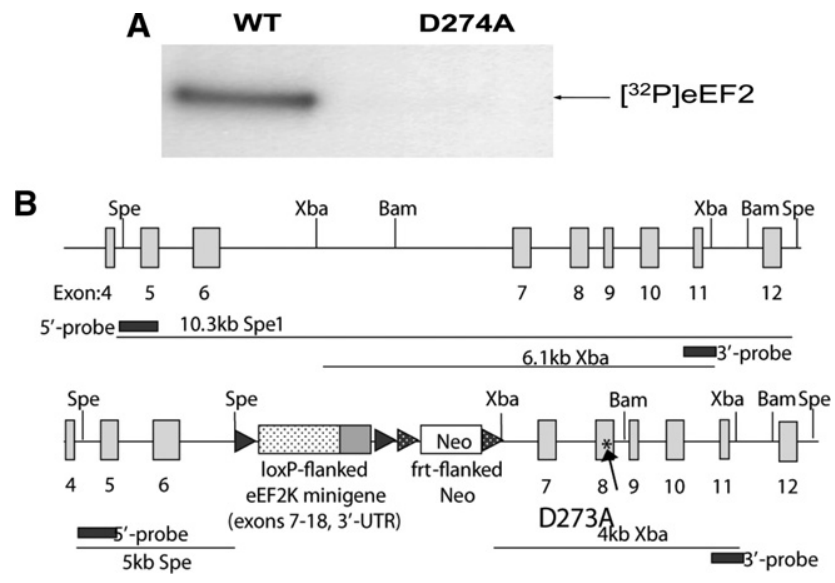

Figure 1. Characterization of eEF2K ki mice. (A) Purified eEF2 was incubated with $\left[{ }^{32} \mathrm{P}\right] \mathrm{ATP}$ and recombinant eEF2K (wild-type or D273A) in the presence of calmodulin and calcium $\left(\mathrm{CaCl}_{2}\right)$ for 5 min, over which period the assay is linear with respect to time. (B) Creation of mice lacking active eEF2 kinase: targeted genome. The figure depicts (cartoon: not to scale) a section of the mouse eEF2 kinase gene in the wild-type (upper) and targeted (lower) forms. The latter includes (1) a minigene comprising exons 718 of the eEF2 kinase gene, flanked by loxP sites; (2) a neomycin-resistant cassette flanked by frt sites; and (3) a mutated form of exon 8, introducing the kinase-dead (KD) D274A mutation (arrow; asterisk). of water for $20 \mathrm{~min}$ from similar pipettes and, 30 min later, were injected with $\mathrm{LiCl}$. Two days after training, a multiple-choice test was performed, in which the mice were offered four pipettes simultaneously-two containing $5 \mathrm{~mL}$ each of a novel taste (CS), and each of the other two containing $5 \mathrm{~mL}$ of water. After training, the conditioned mice preferred water to saccharin in a multiple-choice test, whereas nonconditioned mice preferred saccharin to water.

Behavioral data are presented in terms of an aversion index, defined as: $[\mathrm{mL}$ water/( $\mathrm{mL}$ water $+\mathrm{mL}$ saccharin $)]$ consumed in the test. The higher the aversion index is, the greater the preference of the mice for water over the conditioned taste.

\section{Attenuation of neophobia}

Mice were trained for $3 \mathrm{~d}$ to drink during 20-min periods from two pipettes each containing $5 \mathrm{~mL}$ of water. On day 4 , a multiplechoice test was applied: the mice were offered four pipettes simultaneously; two containing $5 \mathrm{~mL}$ of a novel taste (saccharin $0.5 \%$ $[\mathrm{w} / \mathrm{v}]$ or $\mathrm{NaCl} 0.4 \%[\mathrm{w} / \mathrm{v}]$ ) and the other two containing $5 \mathrm{~mL}$ of water. The behavioral data are presented in terms of an aversion index, defined as above. For long-term taste memory formation, choice tests were applied on four consecutive days and again on the 14th day.

\section{Taste recognition in mice}

In order to address possible differences in the sensory level between the $k i$ and the WT mice, their natural aversion to quinine (bitter taste) was examined. The mice were offered four pipettes simultaneously; two containing $5 \mathrm{~mL}$ of $0.04 \%$ quinine (Fluka) each and the other two containing $5 \mathrm{~mL}$ of water. The aversion index was defined as above.

\section{Mouse genotyping}

\section{Isolation of DNA from mouse tail biopsies}

About $0.3 \mathrm{~cm}$ of tail tissue was placed in an Eppendorf tube with $500 \mu \mathrm{L}$ of TNES (lysis buffer) comprising: $50 \mathrm{mM}$ Tris Base (Sigma), $100 \mathrm{mM}$ EDTA (Fluka), $100 \mathrm{mM} \mathrm{NaCl}$ (Sigma-Aldrich), and $1 \%$ SDS (Amresco), DDW; $20 \mu \mathrm{L}$ of Proteinase K (Fermentas) were added at $10 \mathrm{mg} / \mathrm{mL}$, and the tube was incubated overnight at $55^{\circ} \mathrm{C}$. Then, $150 \mu \mathrm{L}$ of $5 \mathrm{M} \mathrm{NaCl}$ were added, the tubes were shaken vigorously for $15 \mathrm{sec}$ and then centrifuged at 20,000 $\mathrm{g}$ for $5 \mathrm{~min}$ at room temperature. The supernatant was removed to a new Eppendorf and an equivalent volume of isopropanol was added. The Eppendorf was inverted for $15 \mathrm{sec}$ and centrifuged at $20,000 \mathrm{~g}$ for $5 \mathrm{~min}$ at room temperature. The supernatant was discarded, and the pellet was air-dried for $30 \mathrm{~min}$, resuspended in $100 \mu \mathrm{L}$ of ultra-pure water (Biological Industries), and the tubes were heated at $37^{\circ} \mathrm{C}$ for $10 \mathrm{~min}$. The resulting DNA samples were stored at $4^{\circ} \mathrm{C}$ pending typing (Miller et al. 1988).

\section{$P C R$ reaction}

A PCR cocktail was prepared. Each $20-\mu \mathrm{L}$ portion of final PCR reaction mix comprised $6 \mu \mathrm{L}$ of nuclease-free $\mathrm{H}_{2} \mathrm{O}, 10 \mu \mathrm{L}$ of DreamTaq Green Master Mix (Fermentas), $1 \mu \mathrm{L}$ of each primer, and $2 \mu \mathrm{L}$ of tail DNA $(0.05-0.1 \mu \mathrm{L})$. The primers (from Danyel Biotech Ltd., used at $10 \mathrm{pmol} / \mu \mathrm{L}$ ) were:

eEF2K KD Screen1C F: 5'-CCAGGCTCAGTCTGAGTTGC-3', eEF2K KD Screen1C R: 5'-CTGAGTAGCTTCTCTTGCAGC-3'.

PCR cycles ( 30 cycles) comprised 3 min of initialization at $94^{\circ} \mathrm{C}, 30$ sec of denaturation at $94^{\circ} \mathrm{C}, 1 \mathrm{~min}$ of annealing at $60^{\circ} \mathrm{C}, 1 \mathrm{~min}$ of elongation at $60^{\circ} \mathrm{C}$, and a final elongation for $10 \mathrm{~min}$ at $72^{\circ} \mathrm{C}$.

The PCR products were analyzed on agarose gel ( $2 \%)$, and the PCR product results were recorded with a CCD camera (XRS; BioRad). 


\section{Biochemical procedures}

\section{Preparation of total sample}

For biochemical analysis, the brain (naive or following behavioral manipulation) was removed and total cortex tissue, insular cortex (IC), or hippocampus was dissected and homogenized in a glass-Teflon homogenizer in a lysis buffer composed of the following (in $\mathrm{mM}$, unless indicated otherwise): 10 HEPES, 2 EDTA, 2 EGTA, 0.5 DTT, 1\% phosphatase inhibitor cocktail 1 (Sigma), and $1 \%$ protease inhibitor cocktail (Sigma). Protein content was determined by Bradford assay (Bio-Rad). Appropriate volumes of $2 \times$ SDS sample buffer (10\% glycerol, $5 \% \beta$-mercaptoethanol, and $2.3 \% \mathrm{SDS}$, in $62.5 \mathrm{mM}$ Tris- $\mathrm{HCl}, \mathrm{pH} 6.8$ ) were added to the homogenates, and samples were boiled for $5 \mathrm{~min}$ and stored at $-20^{\circ} \mathrm{C}$.

\section{SDS-PAGE and Western blotting}

Aliquots of the homogenate in SDS sample buffer were analyzed by SDS-PAGE and Western blotting. After electrophoresis and electrophoretic transfer, the blots were blocked for $1 \mathrm{~h}$ at room temperature, with agitation, in freshly prepared Tris-buffered saline solution containing $0.1 \%$ Tween 20 (TBST) with 3\%-5\% bovine serum albumin (BSA). The blots were incubated with primary antibody, either overnight at $4^{\circ} \mathrm{C}$ or for $1 \mathrm{~h}$ at room temperature. After three short washes with TBST, the blots were incubated for $1 \mathrm{~h}$ at room temperature with goat anti-rabbit (IgG) horseradish peroxidase (HRP) conjugated antibody (Amersham). The blots were then washed three times in TBST and exposed to enhanced chemiluminescence with an EZ ECL kit (Biological Industries).

\section{Assay of eEF2K activity}

Recombinant human eEF2K was expressed as an N-terminal glutathione S-transferase (GST) fusion protein in bacteria as described earlier (Smith and Proud 2008). The D274A mutant was created by QuikChange (Stratagene) and expressed in a similar way. To assess kinase activity, GST-eEF2K was incubated with purified eEF2 (from HeLa cells (Smith and Proud 2008)). Reaction products were analyzed by SDS- PAGE, followed by analysis using a Typhoon phosphorimager (GE Healthcare).

\section{Reagents}

eEF2 (1:1000), p-eEF2 (1:1000), and eEF2K (1:1000) polyclonal antibodies were obtained from Cell Signaling. $\alpha$-CamKII $(1: 10,000)$ and $\beta$-actin (1:3000) antibodies were obtained from Santa Cruz Biotechnology. Goat anti-rabbit (IgG) HRP conjugated, goat antimouse (IgG) HRP conjugated, and rabbit anti-goat (IgG) HRP conjugated $(1: 10,000)$ were purchased from Chemicon. An Enhanced Chemiluminescence (ECL+) kit was purchased from Amersham.

\section{Quantification}

Quantification was performed with a CCD camera (XRS; Bio-Rad). Each sample was measured relative to the background, and phosphorylation levels were calculated as the ratio between the results obtained with the antibody directed against the phosphoproteins and those obtained with the antibody directed against the phosphorylation-state-independent form of the proteins.

\section{Statistical analysis}

The results were expressed as means \pm SEM. For statistical analysis, the Student's $t$-test, paired $t$-test, and repeated measures were used. Tests were used with an $\alpha$ level of 0.05 .

\section{Manganese-enhanced magnetic resonance imaging tests}

The animals were assigned to one of five groups. One group of 18 naive mice that served for an anatomical background was held in regular housing conditions with no special treatment. The mice of the other four groups were housed in individual cages with access to drinking limited to 20 min per day. After $3 \mathrm{~d}$ of adjustment to their environment, the mice were subjected to the treatments specified below. The four groups were: (1) 19 control WT mice (WT-con); (2) 19 control ki mice (ki-con); (3) 20 CTA-trained WT mice (WT-CTA); and (4) 20 CTA-trained $k i$ mice ( $k i$-con).

Under the 8-d treatment protocol, all the mice received i.p. injections of $10 \mathrm{mM} \mathrm{Mn}^{2+}$ at $2 \%$ of body weight (bw) every other day, starting from day 1 , and all mice were scanned in the MRI on day 8. The CTA groups were given a conditioning treatment comprised of drinking $0.5 \%$ saccharin solution followed by an i.p. injection of $0.14 \mathrm{M} \mathrm{LiCl}$ at $2 \%$ of bw 40 min later, on days 4 and 6 . The control groups received a treatment in which tap water replaced the saccharin solution, and i.p. injections of saline at $2 \%$ of bw instead of LiCl. Water and saccharin intake, as well as weights, were measured and recorded for each animal during each of the seven days. Any animals whose measurements deviated by $>2$ standard deviations from their group mean were excluded from the analysis, which left 18,16, 19, and 17 animals in the WTcon, $k i$-con, WT-CTA, and ki-CTA groups, respectively.

The $\mathrm{Mn}^{2+}$ administration protocol was selected to provide sufficient enhancement of brain tissue signal, i.e., 30\%-50\%, with minimum effect on animal well-being. This criterion was based on reports on fractionated MEMRI in rats (Bock et al. 2008; Inui-Yamamoto et al. 2010), mice (Grünecker et al. 2010), and on our own pilot studies. A stock solution of $10 \mathrm{mM} \mathrm{MnCl} \mathrm{m}_{2}$ (Sigma) in DDW was prepared. Each of four injections was adjusted to $25 \mathrm{mg} / \mathrm{kg}$ (bw), for a total of $100 \mathrm{mg} / \mathrm{kg}$ (bw).

\section{MRI acquisition}

A 7T/30 MRI scanner (Bruker) was used for the MRI experiments. The mice were anesthetized with an i.p. injection of Equitisine (pentobarbital $9.72 \mathrm{mg} / \mathrm{mL}$, chloral hydrate $42.5 \mathrm{mg} / \mathrm{mL}, 86.25 \mathrm{mM}$ $\mathrm{MgSO}_{4}, 10 \%(\mathrm{v} / \mathrm{v})$ ethanol, and $40 \%$ [v/v] propylene glycol) at $0.3 \mathrm{~mL}$ per $100 \mathrm{~g}$ of body weight. The mice were packed, in the prone position, into a custom-made holder that enabled simultaneous imaging of six mice. They were arranged in two triplets facing each other. The positions of mice from the various experimental groups within the holder were counter-balanced across scans. Head movements were limited by fixing the incisors and snout between fishing lines. The holder was fitted into a quadrature transmit-receive coil that measured $94 \mathrm{~mm}$ in length by $72 \mathrm{~mm}$ internal diameter. The whole imaging procedure, from anesthesia induction to placing in a recovery cage, lasted no more than $30 \mathrm{~min}$, and the mice withstood it well.

Following a short localizing sequence, T1-weighted (T1w) brain images were acquired by using a 3D gradient-echo pulse sequence: TR $18.4 \mathrm{msec}$, TE $4.2 \mathrm{msec}, \mathrm{FA} 45^{\circ}$; matrix size $256 \times$ $192 \times 320$, zero-filled to $256 \times 256 \times 320$, field of view $64 \times$ $64 \times 80 \mathrm{~mm}^{3}$, nominal spatial resolution of $0.25 \mathrm{~mm}^{3}$, number of averages 1 , with a total measurement duration of $16 \mathrm{~min}$.

\section{MRI data processing}

Images were reconstructed and processed with Matlab software (MathWorks, Inc.) and the PET module of the SPM5 toolbox (www.fil.ion.ucl.ac.uk/spm). The individual brain images were cropped from the sextet images obtained in the scans and turned to a standard orientation. A representative image of one animal was selected to serve as a template for a first spatial normalization of all mice, followed by a second normalization to the first grandmean image. A second grand mean was then calculated and manually registered onto a standard template extracted from a stereotaxic atlas (Franklin and Paxinos 2007), and the resulting transformation matrix was then used for reorientation of all individual images. All images were bias-corrected. A second set of images with flipped left-right orientation was created, and the corresponding images from the two sets were averaged. A brain mask for the SPM analysis was created based on this mean image (MRIcro; www.sph.sc.edu/comd/rorden/mricro.html). The mean $\mathrm{Mn}^{2+}$-free image was subtracted from each individual image, and the resulting images were spatially smoothed with a $0.8-\mathrm{mm}$ kernel. This final data set was used as the input to the SPM 
model. The model consisted of the animal groups as a five-level, ANCOVA-corrected factor, with the behavioral measurements as regressors. The anatomical structures were manually assigned to the resulting SPM maps according to the mouse stereotaxic atlas (Franklin and Paxinos 2007).

\section{Results}

\section{Generating eEF2K ki mice}

To pinpoint residues in the catalytic domain of human eEF2K that might be critical for activity, we made use of the published crystal structure of the catalytic domain of ChaK1, which is closely related to eEF2K, (Yamaguchi et al. 2001). Several residues which are conserved between ChaK1, eEF2K, and other related kinases were predicted to play a role in interacting with the phosphate groups of the substrate ATP. We mutated several of these individually, expressed the mutant proteins in Escherichia Coli, and tested their activity against eEF2, in comparison to wild-type human eEF2K (data not shown). Several showed greatly decreased activity; in particular, the D274A mutant, which corresponds to D1765 in ChaK1, showed undetectable activity in our standard assay (Fig. 1A). We, therefore, chose to knock the corresponding mutation (D273A) into the mouse eEF2K gene (using the strategy described in Fig. 1B) to create "kinase-dead" eEF2K mice.

The mice were genotyped in order to distinguish among eEF2K ki, WT, and heterozygote mice. Samples from eEF2K WT mice yielded the expected 300-bp-long PCR product, whereas those from eEF2K ki mice yielded a 350-bp product; and both bands were detected in heterozygote mice (data not shown). No differences were identified between $k i$ and WT mice, either in gross brain morphology or in general vitality or fecundity (data not shown).

\section{Residual eEF2 phosphorylation and normal expression of eEF2, eEF2K, and $\alpha$-CaMKII in cortex and hippocampus of eEF2K ki mice}

We first analyzed brain levels of eEF2, eEF2 phosphorylation state (Thr56), eEF2K, and $\alpha$-CaMKII, which were expected to be altered because of the attenuated eEF2 phosphorylation (Belelovsky et al. 2005).

For protein analysis, brain tissue (cortex and hippocampus) was obtained from naive WT and homozygote knock-in ( $k i)$ mice $(n=5)$. Samples were subjected to Western blot analysis and normalized to $\beta$-actin expression, because $\beta$-actin was not altered in transgenic mice (data not shown). In light of this analysis, we saw that there was no difference in expression of eEF2 and eEF2K proteins in either the cortex (eEF2 WT: $1.00 \pm 0.11, n=5$; ki: $1.09 \pm 0.16, n=5$; $t$-test, $t_{(8)}=-0.45, P>0.05$; eEF2K WT: $1.00 \pm 0.12, n=5 ; k i: 1.29 \pm 0.07, n=5$; $t$-test, $t_{(8)}=-1.95, P$ $>0.05$ ) (Fig. 2A) or the hippocampus of transgenic mice (eEF2 WT: $1.00 \pm 0.10, n=5$; ki: $0.91 \pm 0.09, n=5$; $t$-test, $t_{(8)}=0.59$, $P>0.05$; eEF2K: WT: $1.00 \pm 0.7, n=5$; ki: $0.86 \pm 0.12, n=5$; $t$-test, $\left.t_{(8)}=0.91, P>0.05\right)$ (Fig. $2 \mathrm{~B}$ ). From these results, we concluded that the point mutation in the kinase domain of eEF2K did not change the total expression of either eEF2K or eEF2 protein. $\alpha$-CaMKII, a poor initiator and a protein known to be involved in synaptic plasticity, which has previously been found to be modulated following attenuation in eEF2 phosphorylation levels (Belelovsky et al. 2005), was not altered (in cortex WT: $1.00 \pm 0.07, n=5 ; k i: 1.11 \pm 0.09, n=4 ;$-test, $t_{(7)}=-0.92, P$ $>0.05$; in hippocampus WT: $1.00 \pm 0.10, n=5$; ki $1.02 \pm 0.05$; $n=5$; $t$-test, $\left.t_{(8)}=-0.22, P>0.05\right)$ (Fig. $2 \mathrm{~A}, \mathrm{~B}$ ).

In order to ascertain the effect of the D273A knock-in mutation on eEF2 phosphorylation in the homozygote knock-in ( $k i)$ mice, the basal level of phospho-eEF2 was assessed. Samples from cortex and hippocampus of eEF2K WT and $k i$ mice $(n=5)$ were analyzed (Fig. 2C,D). Surprisingly, we detected a band indicating low levels of phosphorylation in eEF2K $k i$ mice (cortex: $0.28 \pm 0.04, n=5$; hippocampus: $0.28 \pm 0.06, n=5$ ). Statistical analysis revealed significant differences between eEF2K $k i$ group and WT mice in p-eEF2 levels in cortex ( $t$-test, $n=5, t_{(8)}=11.8$, $P<0.01$ ) (Fig. 2C) and hippocampus ( $t$-test, $n=5, t_{(8)}=2.9, P$ $<0.05$ ) (Fig. 2D).

One explanation for the low levels of eEF2 phosphorylation in the brain of $k i$ mice could be nonspecific recognition of the eEF2 total protein by the phospho-specific (Thr56) antibody. In order to exclude this possibility, we performed another WB analysis but this time with an additional sample of pure nonphosphorylated eEF2 protein (Fig. 2E). The anti-eEF2 antibody successfully detected pure eEF2 protein and eEF2 in both WT and $k i$ lysates. The anti-p-eEF2 antibody detected p-eEF2 in WT lysate, a lower level of p-eEF2 in $k i$ lysate, and no band in the pure eEF2 protein lane. This suggests that the $k i$ has a residual low level of p-eEF2, which was surprising given the apparent complete loss of eEF2K activity for the D273A mutant. The simplest explanation for this observation is that the eEF2K[D273A] mutant does possess very low residual activity. To assess this, we assayed the activity of wild-type and D273A mutant eEF2 against eEF2 over a wide range of enzyme concentrations. As shown in Figure 2F, at enzyme levels that give high levels of eEF2 phosphorylation when the wild-type enzyme is used, the D273A mutant showed no activity. However, when large amounts of recombinant kinase were used, a trace of eEF2 phosphorylation was observed for the D273A mutant. We estimate, based on multiple assays, that this corresponds to $<0.5 \%$ of the activity of wild-type eEF2K. Thus, while the eEF2K[D273A] mutant has almost completely ( $>99.5 \%)$ lost activity, it does retain some residual function. This explains the residual p-eEF2 observed in samples from the homozygous mutant mice. The fact that even $0.5 \%$ of normal activity results in significant residual eEF2 phosphorylation demonstrates that the steady-state phosphorylation level of eEF2 is very delicately poised, responding even to very low eEF2K activity. Subtle control of eEF2K activity likely plays a key role in determining the levels of active eEF2.

\section{Impaired associative taste learning and normal taste recognition, memory, and correlative induction of eEF2 phosphorylation in eEF2K ki mice}

Increased eEF2 phosphorylation in the GC was correlated with novel taste learning in rats (Belelovsky et al. 2005). We, therefore, tested the following two hypotheses: (1) Novel taste learning is impaired in eEF2K ki mice; and (2) Novel taste learning will induce correlative induction of eEF2 phosphorylation in the GC of WT but not in that of $k i$ mice. During all taste learning experiments, consumption of water or novel taste was measured and compared among the various groups. Mice were weighed and only those that fitted into the normal weight category were used in the experiments. The normal weight category was determined according to a body weight chart for C57Bl6 mice. In addition, average body weight was compared among the various groups to ensure that there were no differences (data not shown).

In order to measure taste learning and memory processes and to exclude the possibility that eEF2K $k i$ and WT mice had different taste preferences, we tested eEF2K WT and ki mice for three different tastes: quinine $0.04 \%$, saccharin $0.5 \%$, and $\mathrm{NaCl} 0.4 \%$. We found that eEF2K ki mice showed the same natural aversion to quinine $(98.4 \pm 0.7 \%, n=8)$ as the WT $(95.1 \pm 1.4 \%, n=8)$, $t$-test, $t_{(14)}=-1.99, P>0.05$. There was no significant difference in taste preference among the groups when either saccharin (WT: $65.7 \pm 9.3 \%, n=10 ; k i: 62.0 \pm 8.8 \%, n=10 ; t$-test, $t_{(18)}=0.29$, $P>0.05$ ) or $\mathrm{NaCl}$ was used as a novel taste (WT: $50.2 \pm 7.3 \%$, 

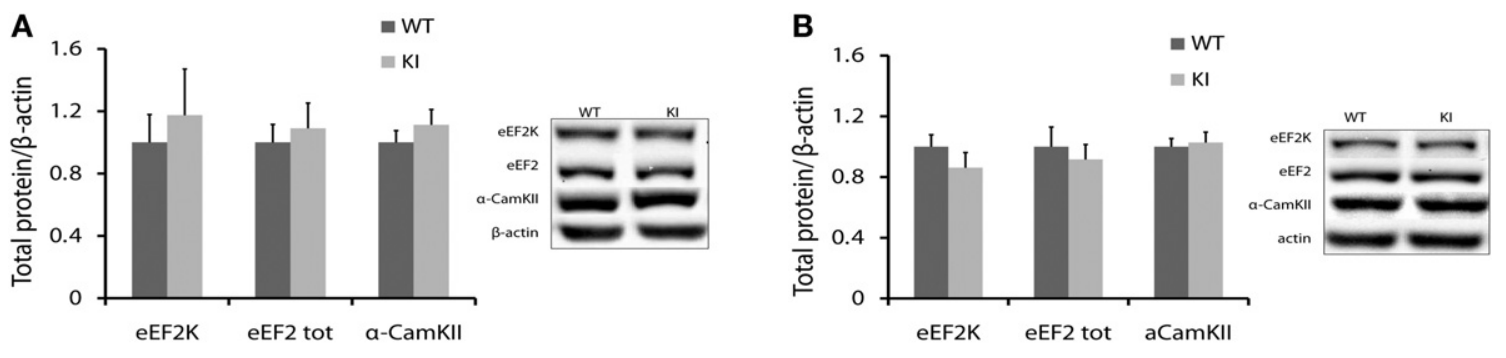

C

D
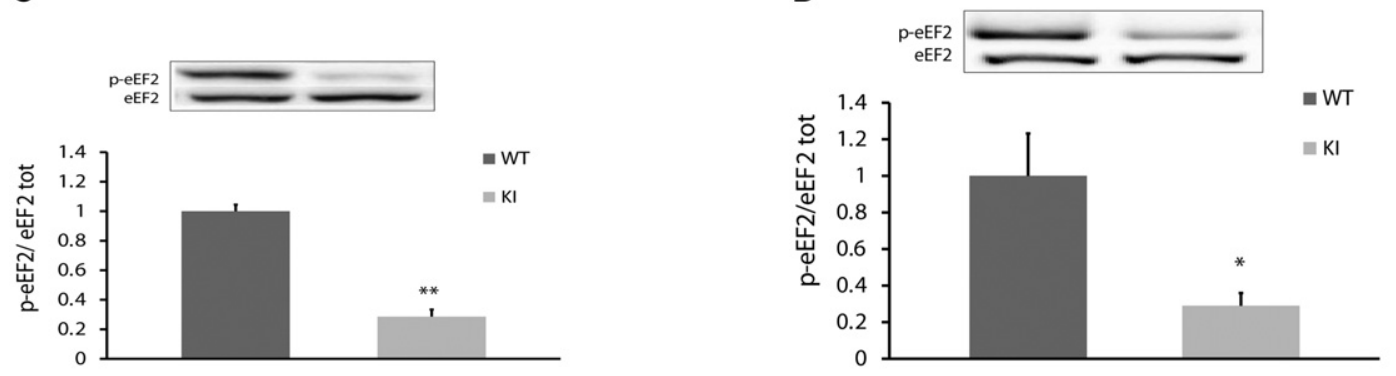

E

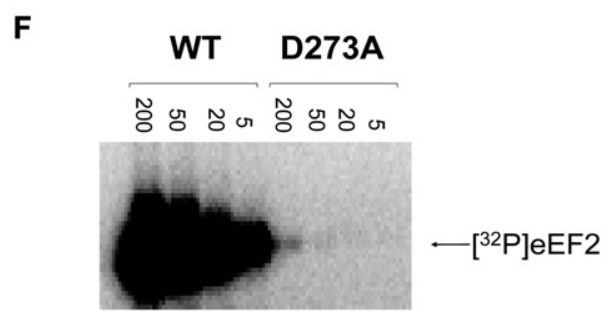

Figure 2. Biochemical analysis of hippocampus and cortex of eEF2K ki mice $(A, B)$ eEF2K, eEF2, and $\alpha$-CaMKII levels in cortex $(A)$ and hippocampus $(B)$ of eEF2K ki mice is normal. Protein levels were normalized to actin and normalized to levels in WT mice. Summary data and representative blots are shown. There is no difference in eEF2K, eEF2, and $\alpha$-CamKIl levels between two mouse types; $t$-test, $n=5, P>0.05$. $(C, D)$ p-eEF2 levels in cortex $(C)$ and hippocampus $(D)$ of eEF2K ki mice are reduced. Summary data and representative immunoblots are shown. Data are presented as the ratio of p-eEF2-to-eEF2 and normalized to levels of $p$-eEF2 in WT mice. There are significantly lower levels of p-eEF2 in eEF2K $k i$ mice; $t$-test, $n=5, * P<0.05, * * P<0.01$. (E) eEF2 phospho-specific antibody (for Thr56 in eEF2) does not react with nonphosphorylated eEF2 protein in Western blot analysis. Immunoblots of eEF2 protein and p-eEF2 for brain and pure protein samples are shown. $(F)$ Purified eEF2 was incubated with $\left[{ }^{32}\right.$ P]ATP and the indicated amount of recombinant eEF2K (wild-type or D273A) in the presence of calmodulin and calcium $\left(\mathrm{CaCl}_{2}\right)$ for $5 \mathrm{~min}$.

$n=16$; $k i: 52.4 \pm 5.1 \%, n=16$; $t$-test, $P>0.05)$. We concluded that eEF2K ki mice have normal native taste recognition and taste preference.

In order to test the hypothesis that taste memory per se, i.e., incidental taste memory, is impaired in the ki mice, we examined the reduction in neophobia by using saccharin as a novel taste (Merhav and Rosenblum 2008). No differences in aversion index were found during four consecutive days following the first taste exposure (Fig. 3A) (repeated measures test, between-subject effect: $\left.F_{(1,18)}=0.33, P>0.05\right)$, indicating normal long-term taste memory formation and consolidation in the transgenic mice. The repeated measures test was performed for each group to evaluate LTM formation for all test days (within-subjects effect, $F_{(4,72)}=$ 7.83, $P<0.01)$. LTM formation for novel taste was similar for both groups (Fig. 3B). Comparison between the first and 14th test days (paired $t$-test: $n=10$; for WT: $t_{(9)}=4.60, P<0.01$; for ki: $\left.t_{(9)}=3.24, P<0.05\right)$ showed a significant decrease in aversion to saccharin in both groups, indicating normal long-term taste memory. We thus refuted the hypothesis that eEF2K $k i$ mice have abnormal long-term taste memory formation.

Next, we tested the hypothesis that WT and eEF2K ki mice would show similar increases in eEF2 phosphorylation in the GC following novel taste learning (Fig. 3B). The mice were trained to drink from pipettes for $3 \mathrm{~d}$, and 20 min following their consumption of a novel taste (saccharin $0.5 \%$ ), their GC and control cortices were removed and analyzed for eEF2 phosphorylation. There were significant increases in p-eEF2 in both WT and $k i$ mice (WT: $29 \pm 10 \%$, $t$-test, $t_{(16)}=-2.27, n=9, P<0.05$; $k i$ : $40 \pm 12 \%$, $t$-test, $t_{(16)}=-2.63, n=9, P<0.02$ ) (Fig. 3C). Total levels of eEF2 protein remained unaltered in both WT $(0.90 \pm 0.1$, $n=9$, $t$-test, $\left.t_{(16)}=0.66, P>0.05\right)$ and $k i$ mice $(0.95 \pm 0.10, n$ $=9, t$-test, $\left.t_{(16)}=0.37, P>0.05\right)$. In addition, we examined p-eEF2 elevation in a related cortical region, the occipital lobe, at the same time point, to verify restriction of the modulation to the GC and saw no elevation of p-eEF2 in either WT $(0.79 \pm$ $0.06, t$-test, $n=4, P>0.05)$ or $k i$ mice $(0.97 \pm 0.1, t$-test, $n \geq 4$, $P>0.05)$. The results demonstrated that the eEF2 correlative induction in phosphorylation in the GC following novel taste learning that was observed in the rat (Belelovsky et al. 2005) also occurred in mice.

It could be suggested that levels of eEF2 phosphorylation play a specific role in associative but not incidental learning. We, therefore, compared conditioned taste aversion learning between the $k i$ and the WT littermate mice to test our hypothesis that $k i$ mice would be impaired in CTA learning. Five independent experiments were performed, and the data shown here constitute a summation of them all (Fig. 4). On the conditioning day, the animals received saccharin as a novel taste, and the total amounts consumed were similar in the two groups (WT: $1.46 \pm 0.07 \mathrm{~mL}$, $n=28$; ki: $1.54 \pm 0.05 \mathrm{~mL}, n=30$; $t$-test, $P>0.05)$. Following 
A

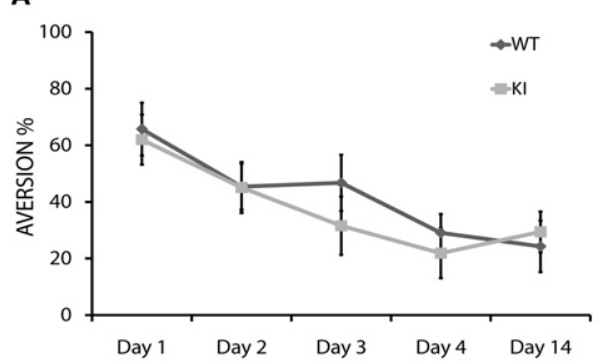

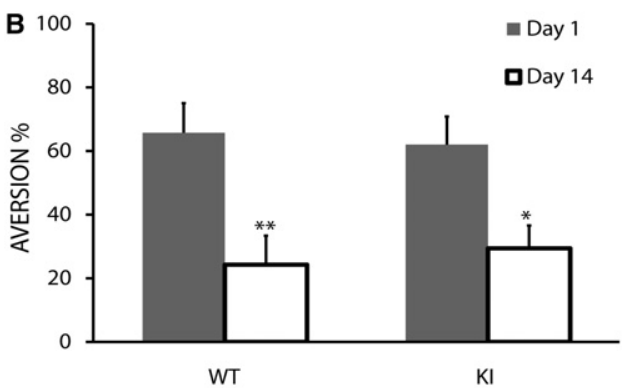
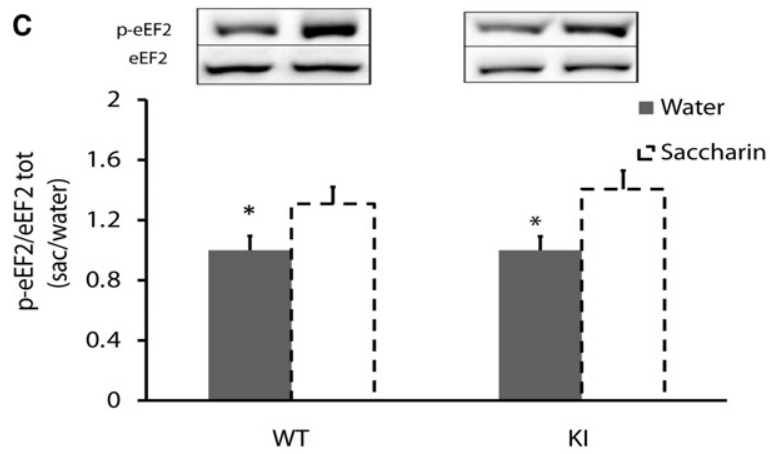

Figure 3. Normal long-term taste memory in eEF2K ki mice. ( $A$ ) $Y$-axis is aversion percentage. There is no difference in attenuation of neophobia for saccharin between the two groups on any test day (ANOVA repeated measures, $n=10, P>0.05$ ); there is a significant decrease in aversion index for both groups $(P<0.05)$. (B) $Y$-axis is aversion percentage. Comparison between aversion indexes on the first test day and 14 th test day (same data as in $A$ ) during taste learning in transgenic mice (paired $t$-test, $n=10, * P<0.05$, ${ }^{* *} P<0.01$ ), which revealed normal long-term taste memory. (C) p-eEF2 level in GC following novel taste learning. eEF2 phosphorylation increased in the GC within 20 min after novel taste learning in transgenic mice. Representative immunoblots of anti-protein antibody and phospho-specific antibody (Thr56) are presented. Protein levels (p-eEF2/eEF2) are expressed as the ratio between saccharin and water values. Values $=1$ indicate no increase or decrease; values $>1$ indicate an increase in protein phosphorylation ( $t$-test, $n=9, * p<0.05$ ).

CTA, the $k i$ mice exhibited impaired CTA learning $(66.9 \pm 4.7 \%$, $n=30)$ compared to the WT $\left(84.4 \pm 3.0 \%, n=28\right.$; $t$-test, $t_{(56)}=$ 3.06, $P<0.01$ ) (Fig. 4). Statistical analysis indicates a significant difference between the eEF2K $k i$ group and the eEF2K WT group. In order to determine whether $k i$ mice exhibited partial CTA learning or no CTA at all, we compared the aversion index that followed CTA learning (i.e., that on the first test day which was a second exposure to the novel taste) with that following incidental taste learning (i.e., on the second test day) in transgenic mice. Statistical analysis showed that $k i$ mice did exhibit CTA learning but at a significantly lower level than the WT mice (CTA in ki: $66.9 \pm 4.7 \%, n=30$; taste learning in $k i$ (second test day): $45.0 \pm 9.0 \%, n=10$; $t$-test, $\left.t_{(38)}=-2.25, P<0.05\right)$. Following the observation that the $k i$ mice were impaired in associative but not in incidental learning, we tested the hypothesis that brain activity was abnormal in the $k i$ during CTA learning but not under basal conditions.

\section{Brain activation under basal conditions as measured in MEMRI is normal in eEF2k ki mice}

In order to measure and compare the patterns of brain activation in the mice, we adopted the MEMRI protocol to implement the fractionated mode of systemic $\mathrm{Mn}^{2+}$ administration (Kuo et al. 2005; Grünecker et al. 2010; Inui-Yamamoto et al. 2010). When administered systemically, $\mathrm{Mn}^{2+}$ reaches the brain and enters the cells via voltage-gated $\mathrm{Ca}^{2+}$ channels and then propagates transsynaptically. Most importantly, because the transfer of manganese is through voltage-gated channels at relatively low rates, its accumulation inside cells and in the surrounding extracellular space is proportional to neural activity (Lin and Koretsky 1997;
Eschenko et al. 2009). We chose this MEMRI mode, which measures accumulation of $\mathrm{Mn}^{2+}$ in active brain regions over several days, to provide a global view of patterns of brain activation associated with repeated CTA training. The imaging data were statistically analyzed with the well-accepted SPM toolbox. First, we examined the basal pattern of brain activation that was obtained following manganese injection. This was done by contrasting the signal intensities in brains of all mice injected with $\mathrm{Mn}^{2+}$ with those in the brains of $\mathrm{Mn}^{2+}$-free, control mice.

The i.p. injections of $10 \mathrm{mM} \mathrm{Mn}^{2+}$ at $2 \%$ of bw caused an average increase in brain signal intensity of $53 \pm 12 \%$, with a typical distribution across the brain regions (Fig. 5; Kuo et al. 2005). The statistical maps show a highly significant signal increase throughout the brain. However, raising the statistical threshold to a very

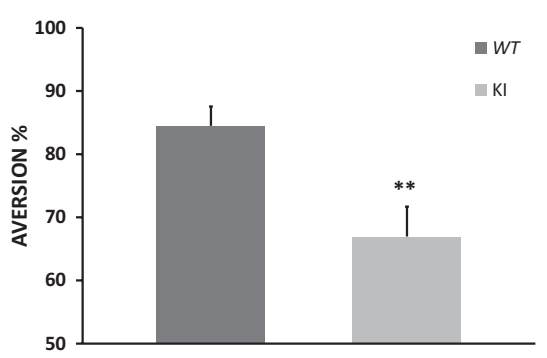

Figure 4. eEF2K $k i$ mice are impaired in CTA learning. Presented is a summary of five independent experiments. $Y$-axis indicates aversion percentage. eEF2K ki group exhibits lower aversion index than WT group following CTA training ( $t$-test, $n \geq 28, * * P<0.01$ ). 

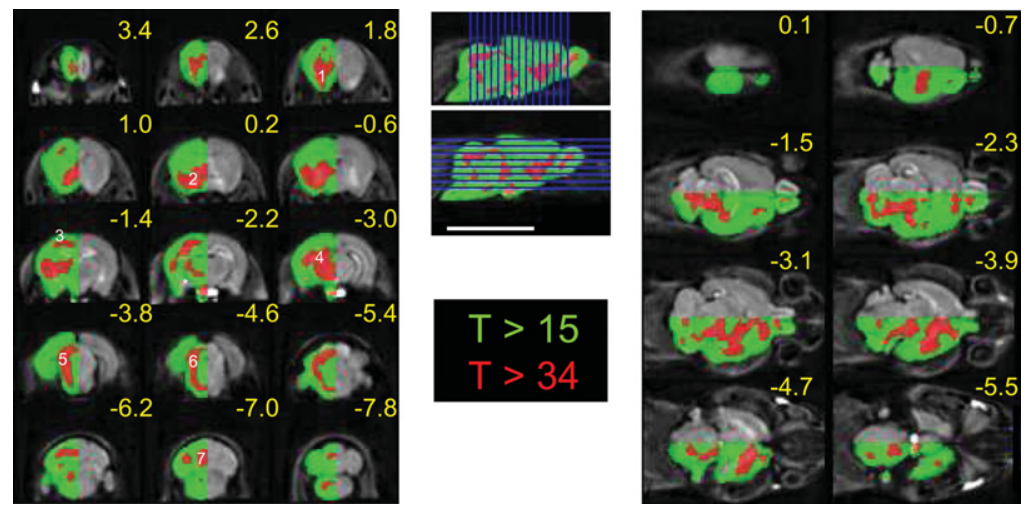

Figure 5. High MEMRI signal following fractionated i.p. injections of $\mathrm{MnCl}_{2}$, with predilection for particular brain regions. Coronal (left) and axial (right) slices with indicated positions relative to bregma. Enhanced MRI signal was observed throughout the brain following i.p. injection of $10 \mathrm{mM} \mathrm{Mn}^{2+}$ on alternate days. Gray-scaled half-brain depicts net $\mathrm{Mn}^{2+}$ enhancement obtained by subtracting the mean image of all mice in the $\mathrm{Mn}^{2+}$-injected group from that of those in the noninjected group. The statistical map comparing the net signals of the two groups, overlaid on the other half-brain, shows a very significant enhancement throughout the brain (green, $T$ value $>15$ ). Further increasing the statistical threshold (red, $T>34$ ) demonstrates predisposition to $\mathrm{Mn}^{2+}$ enhancement in specific regions: he olfactory pathway (1), basal ganglia (2), primary sensory cortex (3), midbrain (4), tectum (5), lateral pontine region (6), and cerebellum (7). Lower significance of $\mathrm{Mn}^{2+}$ enhancement at the base of the brain $\left(^{*}\right)$ was due to variability in the MRI signal caused by air in the adjacent external ear canal. Localization of slices is shown on the midsagittal slice. Bar $=10 \mathrm{~mm}$.

high level $(T>34)$ distinguished particular regions from the rest of the brain (Fig. 5). Thus, the basal condition of these regionsthe olfactory pathway, primary sensory cortex, basal ganglia, thalamus, tectum, midbrain, and cerebellum-may be more active than other brain regions.

There was no difference in basal brain activity between the eEF2K ki group and the eEF2K WT group. This was demonstrated by means of similar activation maps, obtained when either of these mouse groups was compared with the control, $\mathrm{Mn}^{2+}$-naive mice, and by lack of statistical difference in direct comparison between the WT and $k i$ groups. clusters were still confluent (Fig. 6, cyan/magenta).

In order to examine how the modified eEF2 pathway affected the MEMRI signal, we compared the eEF2K $k i$ and WT groups. As noted above, there was no significant difference between these two types of mice when they underwent the control procedure. However, the CTA procedure induced a stronger MEMRI signal in the eEF2K ki mice than in the WT group (Fig. 7, cyan). Again, a lower threshold (FDR $P<0.05$ ) demonstrated a nonlocalized global signal, whereas application of a higher threshold (FWE corrected, $P<0.05$ ) resulted in clusters of increased signal in the piriform cortex, posterior insular cortex, basal ganglia, hippocampus, and brainstem (Fig. 7, magenta).

\section{Discussion}

Taste learning paradigms in rodents are useful for defining molecular and cellular processes that underlie learning and memory in the cortex (for reviews, see Rosenblum 2008; Núñez-Jaramillo et al. 2010; Gal-Ben-Ari and Rosenblum 2011), including translation initiation and elongation regulation during memory consolidation (Belelovsky et al. 2005, 2007, 2009; Costa-Mattioli et al. 2007). Taste learning can be positive, i.e., a given taste is learned and tagged as safe or familiar, or negative, i.e., a given taste is associated with malaise and thus tagged as negative and to be avoided in light of the associative experience. Conditioned taste aversion, the association between novel taste and malaise, is a form of associative learning with high ecological significance (Bureš et al. 1998); it is characterized by many similarities to other
CTA induces abnormal (diffuse and increased) brain activity in the eEF2K ki mice as measured in MEMRI In order to determine the effect of the CTA procedure on the MEMRI signal, we compared the images of the CTA mice with those of the controls; the comparison was done separately for the WT and $k i$ mice. When a relatively low statistical threshold was applied, to account for a false detection rate (FDR) of 0.05 , the CTA procedure in both WT and $k i$ mice was associated with a global, nonlocalized MEMRI signal. Raising the statistical threshold to provide family-wise error rate correction (FWE, $P<0.05$ ) in WT mice confined the increased signal to several localized clusters. These clusters included the anterior forebrain, sensory cortex, medial anterodorsal thalamus, lateral midbrain, and pons (Fig. 6 , green/red). Conversely, in ki mice, only a much higher threshold (FWE, $P<$ 0.00001) revealed some localization of the MEMRI signal, but even then, the
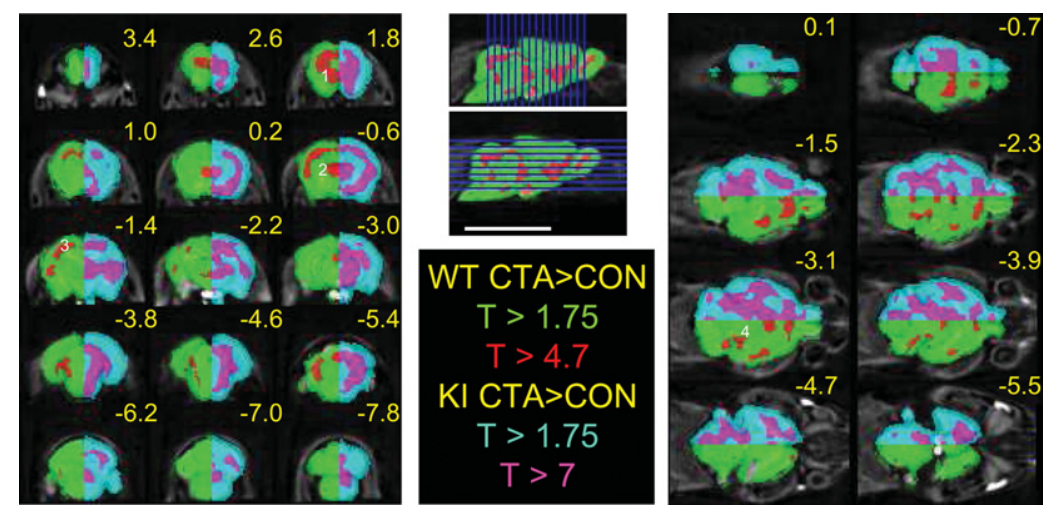

Figure 6. CTA-associated MEMRI signal is higher but less localized in eEF2K $k i$ than in WT mice. Statistical maps derived from the comparisons between groups of mice that underwent CTA and control mice that received i.p. injections of saline instead of $\mathrm{LiCl}$ as the unconditioned stimulus. Enhanced MRI signal associated with the CTA procedure can be localized to discrete regions in WT mice (green-red half-brain) but shows a widespread pattern in eEF2K ki mice (cyan-magenta half-brain). Maps of minimum significance threshold $(P<0.05$, FDR corrected, $T>1.75)$ cover most of the brain in WT mice (green) and even more so in ki ones (cyan). In WT mice, localized enhancements (red) in the anterior forebrain (1), sensory cortex (2), antero-dorso-medial thalamus (3), and lateral midbrain and pons (4) are seen by applying the conventional statistical threshold $(P<0.05$, FWE corrected, $T>$ 4.7). Conversely, confluent $\mathrm{Mn}^{2+}$ enhancement (magenta) remains in ki mice even following application of an extremely high statistical threshold $(P<0.05$, FWE corrected, $T>7)$. 

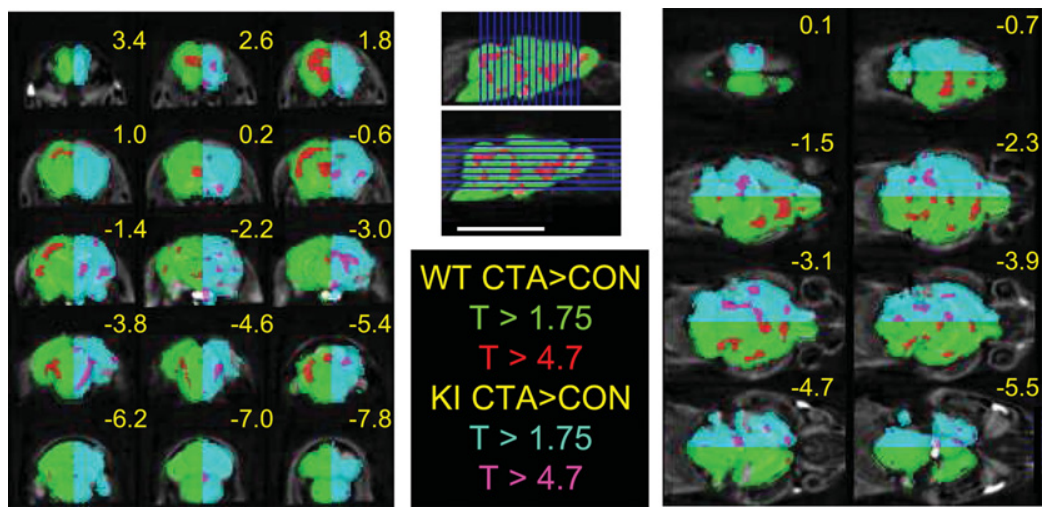

Figure 7. CTA-associated MEMRI signal is stronger in eEF2K ki than in WT mice. The statistical map compares $\mathrm{Mn}^{2+}$ accumulation in the groups of WT and ki mice undergoing the CTA procedure (cyanmagenta half-brain). The minimum statistical threshold map $(P<0.05$, FDR corrected, $T<1.75)$ depicts the generalized, greater increase in $\mathrm{Mn}^{2+}$ accumulation in $k i$ mice (cyan). Several isolated regions of augmented $\mathrm{Mn}^{2+}$ accumulation in this group of mice (magenta) persisted even after application of a higher threshold $(P<0.05$, FWE corrected, $T<4.7)$. The green-red half-brain is as in Figure 5 . CTA-associated activation in WT mice prevails rostro-dorsally (red), whereas in ki mice, CTA-associated enhanced $\mathrm{Mn}^{2+}$ accumulation is more abundant ventro-caudally (magenta).

forms of associative learning but is unique in the long (hours) delay between the conditioned stimulus and the unconditioned stimulus (Rosenblum 2008). Local microinjection of protein synthesis inhibitor into the gustatory cortex before or just after acquisition attenuated long- but not short-term taste memory (Rosenblum et al. 1993; Houpt and Berlin 1998; Merhav and Rosenblum 2008). This indicates that protein synthesis inhibitors did not affect normal neuronal function in the cortex but attenuates specifically memory consolidation.

Detailed analysis of different components of the translation machinery in the GC, following novel taste learning, revealed increased and decreased markers for the initiation and elongation phases of translation, respectively (Belelovsky et al. 2005, 2007, 2009; Costa-Mattioli et al. 2007). This dual regulation of translation was localized both to the soma and to the dendrites of the GC. One may interpret these results as a molecular mechanism that enhances the expression of a specific set of mRNAs that can be regarded as poor initiators (Belelovsky et al. 2005). In cell culture, activation of NMDARs resulted in eEF2 phosphorylation that caused attenuated elongation and decreased total protein synthesis but increased synthesis of a known poor initiator, $\alpha$-CaMKII (Scheetz et al. 2000). It is yet to be determined if the correlative increase in eEF2 phosphorylation following chemical stimulation or learning reflects a mechanism to increase expression of a specific set of proteins or decreased expression of a memory consolidation repressor.

Chotiner et al. (2003) suggested that regulation at the elongation step of protein synthesis, via increased phosphorylation of eEF2, contributes to persistent forms of long-term potentiation (LTP) and simultaneously increases synthesis of the Arc/arg3.1 protein-also known as a poor initiator. Indeed, lack of eEF2 phosphorylation in dendrites resulted in impaired mGluR-LTD and absence of rapid Arc translation (Park et al. 2008).

Moreover, following intrinsic action potential-mediated network activity, eEF2 phosphorylation was shown to be differentially regulated compared to spontaneous neurotransmitter release in hippocampal dendrites. These results suggest that eEF2 is a biochemical sensor that is specifically and locally tuned to the quality of neurotransmission (Sutton et al. 2007). It was shown recently (Verpelli et al. 2010) that the eEF2K/eEF2 pathway is responsible for coupling the neuronal activity to spine plasticity by controlling the dendritic translation of brain-derived neurotropic factor the similarity on the similarity of the degrees of correlative induction of eEF2 phosphorylation in the GC of WT and ki mice (Fig. 3). Thus, although the basal levels of eEF2 phosphorylation in the GC were lower in $k i$ than in WT mice, novel taste learning induced a proportional increase in eEF2 phosphorylation $(\sim 40 \%)$ in the GC in both mouse strains. This suggests that the residual phosphorylation in $k i$ mice together with the similar change in eEF2 phosphorylation is sufficient for long-term taste-memory consolidation (Fig. 3C). However, the increase in eEF2 was insufficient for the learning of CTA; the $k i$ animals were clearly impaired in this behavioral task (Fig. 4). These differential effects can be explained by the different brain areas involved in incidental taste learning versus the associative learning involved in CTA, for example, in the hippocampus (Rosenblum 2008; Gal-Ben-Ari and Rosenblum 2011). Moreover, the fact that, in the $k i$ mice, novel taste learning is normal while CTA is not suggests that levels of eEF2 phosphorylation together with other translation factors determine a differential translation rate and regulation in different brain structures. In addition, a possible system-level basis for the behavioral phenotype of the ki mice can be inferred from the role ofeEF2 phosphorylation in general brain function (Sutton et al. 2007; Verpelli et al. 2010). In order to further pursue the notion of a system-level effect of the genetic inactivation of eEF2K, we examined global patterns of brain activation by using MEMRI.

MEMRI is being increasingly used in animal models because of its T1 contrast, which is sensitive to a number of biological processes (Lin and Koretsky 1997; Silva et al. 2004) and, therefore, can serve as a valuable method for in vivo visualization of functional neuroanatomy. $\mathrm{Mn}^{2+}$ enters excitable cells through voltage-gated $\mathrm{Ca}^{2+}$ channels and is sequestered in $\mathrm{Ca}^{2+}$-containing organelles. In neurons, these organelles are transported along axons, and their $\mathrm{Mn}^{2+}$ content is transferred across active synapses to the next neuron (Pautler et al. 1998; Pautler 2004; Serrano et al. 2008). Thus far, three specific uses of MEMRI in imaging the animal brain have been demonstrated. First, protocols have been devised that enable accumulation of $\mathrm{Mn}^{2+}$ in active areas of the brain; these protocols are based on $\mathrm{Mn}^{2+}$ entry into excitable cells via voltage-gated calcium channels. This technique has been referred to as activation-induced MEMRI (Aoki et al. 2004; Weng et al. 2007). The second use of MEMRI, which relies on transsynaptic transmission of $\mathrm{Mn}^{2+}$, is to trace specific neuronal connections in the brain; it has been shown to enable imaging of 
functional pathways after direct application of $\mathrm{MnCl}_{2}$ into a specific brain region (Pautler et al. 1998; Pautler 2004). The third use of MEMRI, which exploits all the unique characteristics of $\mathrm{Mn}^{2+}$ handling by brain tissue, has been as a whole-brain contrast agent after systemic administration; this has been demonstrated in mice and rats in which an intraperitoneal, intravenous, or subcutaneous injection of $\mathrm{MnCl}_{2}$ has led to unique MRI contrast in the brain (Kuo et al. 2005; de Sousa et al. 2007; Silva and Bock 2008).

As a first step toward understanding the neural substrate that subserves a complex learning procedure represented by CTA, and the difference between WT and eEF2K ki mice, we chose to obtain a global view of the modification of brain activation during the process. The fractionated $\mathrm{Mn}^{2+}$ protocol was best suited for this purpose as it provides a slow, continuous inflow of $\mathrm{Mn}^{2+}$ into brain neurons throughout the several days of the CTA training procedure. Thus, this mode of $\mathrm{Mn}^{2+}$ application was expected to result in a final spatial distribution pattern that reflected the differential cumulative activation of brain regions that is associated with CTA. Similar protocols have been applied to studying activation of the rat brain by voluntary running (Eschenko et al. 2009), auditory stimulation (Yu et al. 2011), and retrieval of novel taste (Inui-Yamamoto et al. 2010).

The basic observation was that dysfunctional eEF2K did not hinder normal development, routine behavior, and even instinctive cautious reactions to unfamiliar, potentially harmful situations such as neophobia. In MEMRI mapping, this basic behavioral similarity between WT and ki mice appeared as statistically nondiffering $\mathrm{Mn}^{2+}$ accumulation patterns in these two groups in the control condition. In this condition, $\mathrm{Mn}^{2+}$ accumulated throughout the brain, but excess accumulation was noted in the somato-sensory and olfactory regions (Fig. 6). The finding of much lower basal eEF2 phosphorylation in $k i$ than in WT mice and normal brain activity as reflected in the MEMRI is consistent with the accepted convention that the rate-limiting step of general, basal protein synthesis is the initiation, and not the elongation, phase (Sonenberg et al. 2000). It may be the case that the regulation of translation elongation is important primarily in certain cell types or under specific conditions.

The CTA training procedure induced significant accumulation of $\mathrm{Mn}^{2+}$ in both WT and ki mice, but the two groups differed in that localizability of $\mathrm{Mn}^{2+}$ to specific brain regions was observed only in the WT group (Fig. 7). The MEMRI mapping further implied that this expression switch occurs in specific regions (Fig. 7). Furthermore, we could argue that, in the case of CTA learning, the ultimate target for behavioral alteration comprises dorsal-anterior brain regions. This hypothesis is based on the comparison between the WT and ki groups under the CTA conditions, which showed global increases in $\mathrm{Mn}^{2+}$ accumulation in the latter but relatively more pronounced accumulation in ventral-posterior regions, so that the anterior regions that participate in CTA learning were spared (Fig. 7). The present findings demonstrate the global effects of a CTA procedure and genetic manipulations of the translation machinery on brain activation, and they direct attention to brain regions beyond the primary gustatory pathways, e.g., the frontal and orbital cortex, as candidates for further biochemical and molecular assays. Clearly, new tools and methods to measure de novo protein synthesis in different brain areas will enable us to draw a clear line between eEF2 phosphorylation levels, the rates of synthesis of specific proteins, and memory consolidation processes in health and disease (Auerbach et al. 2011).

In addition, further analysis is needed to determine whether the different patterns of brain activation and attenuation of CTA learning in the ki mice compared to those in the wild type can be attributed to the general role eEF2 plays in decoding synaptic input (Sutton et al. 2007), BDNF expression (Verpelli et al. 2010), or mGluR-dependent LTD (Park et al. 2008).

\section{Acknowledgments}

This work was supported by an ISF, Extended Psychobiology grant to K.R., Wellcome Trust Programme Grant to C.G.P., and ERANET system biology (SYNSYS) grants to C.G.P. and K.R. We thank Dr. Gad Kenan and Josef Arzuan and the Laboratories of the Psychology Department, University of Haifa, for the design and fabrication of the six-mouse holder.

\section{References}

Abel T, Lattal KM. 2001. Molecular mechanisms of memory acquisition, consolidation, and retrieval. Curr Opin Neurobiol 11: 180-187.

Alberini CM. 2005. Mechanisms of memory stabilization: Are consolidation and reconsolidation similar or distinct processes? Trends Neurosci 28: $51-56$.

Aoki I, Naruse S, Tanaka C. 2004. Manganese-enhanced magnetic resonance imaging (MEMRI) of brain activity and applications to early detection of brain ischemia. NMR Biomed 17: 569-580.

Auerbach BD, Osterweil EK, Bear MF. 2011. Mutations causing syndromic autism define an axis of synaptic pathophysiology. Nature 480: 63-68.

Bailey CH, Bartsch D, Kandel ER. 1996. Toward a molecular definition of long-term memory storage. Proc Natl Acad Sci 93: 13445-13452.

Belelovsky K, Elkobi A, Kaphzan H, Nairn AC, Rosenblum K. 2005. A molecular switch for translational control in taste memory consolidation. Eur J Neurosci 22: 2560-2568.

Belelovsky K, Maroun M, Rosenblum K. 2007. MAPK activation in the hippocampus in vivo is correlated with experimental setting. Neurobiol Learn Mem 88: 58-64.

Belelovsky K, Kaphzan H, Elkobi A, Rosenblum K. 2009. Biphasic activation of the mTOR pathway in the gustatory cortex is correlated with and necessary for taste learning. J Neurosci 29: 7424-7431.

Bock N, Paiva F, Silva A. 2008. Fractionated manganese-enhanced MRI. NMR Biomed 21: 473-478.

Bureš JB, Bermúdez-Rattoni F, Yamamoto T. 1998. Conditioned taste aversion. Memory of special kind. Oxford University Press, New York.

Carlberg U, Nilsson A, Nygard O. 1990. Functional properties of phosphorylated elongation factor 2. Eur J Biochem 191: 639-645.

Chotiner JK, Khorasani H, Nairn AC, O'Dell TJ, Watson JB. 2003. Adenylyl cyclase-dependent form of chemical long-term potentiation triggers translational regulation at the elongation step. Neuroscience 116: $743-752$.

Costa-Mattioli M, Gobert D, Stern E, Gamache K, Colina R, Cuello C, Sossin W, Kaufman R, Pelletier J, Rosenblum K, et al. 2007. eIF2alpha phosphorylation bidirectionally regulates the switch from short- to long-term synaptic plasticity and memory. Cell 129: 195-206.

Debiec J, LeDoux JE, Nader K. 2002. Cellular and systems reconsolidation in the hippocampus. Neuron 36: 527-538.

de Sousa PL, de Souza SL, Silva AC, de Souza RE, de Castro RM. 2007. Manganese-enhanced magnetic resonance imaging (MEMRI) of rat brain after systemic administration of $\mathrm{MnCl}_{2}$ : Changes in T1 relaxation times during postnatal development. J Magn Reson Imaging 25: $32-38$.

Dudai Y. 2004. The neurobiology of consolidations, or, how stable is the engram? Annu Rev Psychol 55: 51-86.

Elkobi A, Ehrlich I, Belelovsky K, Barki-Harrington L, Rosenblum K. 2008. ERK-dependent PSD-95 induction in the gustatory cortex is necessary for taste learning but not retrieval. Nat Neurosci 11: 1149-1151.

Eschenko O, Canals S, Simanova I, Beyerlein M, Murayama Y, Logothetis NK. 2009. Mapping of functional brain activity in freely behaving rats during voluntary running using manganese-enhanced MRI: Implication for longitudinal studies. Neuroimage 49: 2544-2555.

Franklin K, Paxinos G. 2007. The mouse brain in stereotaxic coordinates, 3rd ed. Academic Press, New York.

Gal-Ben-Ari S, Rosenblum K. 2011. Molecular mechanisms underlying memory consolidation of taste information in the cortex. Front Behav Neurosci 5: 87. doi: 10.3389/fnbeh.2011.00087.

Grünecker B, Kaltwasser SF, Peterse Y, Sämann PG, Schmidt MV, Wotjak CT, Czisch M. 2010. Fractionated manganese injections: Effects on MRI contrast enhancement and physiological measures in C57BL/6 mice. NMR Biomed 23: 913-921.

Houpt TA, Berlin R. 1998. Rapid labile and protein synthesisindependent short-term memory in conditioned taste aversion. Learn Mem 6: 37-46.

Inui-Yamamoto C, Yoshioka Y, Inui T, Sasaki KS, Ooi Y, Ueda K, Seiyama A, Ohzawa I. 2010. The brain mapping of the retrieval of conditioned taste aversion memory using manganese-enhanced magnetic resonance imaging in rats. Neuroscience 167: 199-204.

Kanhema T, Dagestad G, Panja D, Tiron A, Messaoudi E, Håvik B, Ying SW, Nairn AC, Sonenberg N, Bramham CR. 2006. Dual regulation of translation initiation and peptide chain elongation during 
BDNF-induced LTP in vivo: Evidence for compartment-specific translation control. J Neurochem 99: 1328-1337.

Kuo YT, Herlihy AH, So PW, Bhakoo KK, Bell JD. 2005. In vivo measurements of T1 relaxation times in mouse brain associated with different modes of systemic administration of manganese chloride. J Magn Reson Imaging 21: 334-339.

Lin YJ, Koretsky AP. 1997. Manganese ion enhances T1-weighted MRI during brain activation: An approach to direct imaging of brain function. Magn Reson Med 38: 378-388.

Marin P, Nastiuk KL, Daniel N, Girault JA, Czernik AJ, Glowinski J, Nairn AC, Premont J. 1997. Glutamate-dependent phosphorylation of elongation factor- 2 and inhibition of protein synthesis in neurons. J Neurosci 17: 3445-3454.

Merhav M, Rosenblum K. 2008. Facilitation of taste memory acquisition by experiencing previous novel taste is protein-synthesis dependent. Learn Mem 15: 501-507.

Miller SA, Dykes DD, Polesky HF. 1988. A simple salting out procedure for extracting DNA from human nucleated cells. Nucl Ac Res 16: 1215. doi: 10.1093/nar/16.3.1215.

Núñez-Jaramillo L, Ramírez-Lugo L, Herrera-Morales W, Miranda MI. 2010. Taste memory formation: Latest advances and challenges. Behav Brain Res 207: 232-248.

Park S, Park JM, Kim S, Kim JA, Shepherd JD, Smith-Hicks CL, Chowdhury S, Kaufmann W, Kuhl D, Ryazanov AG, et al. 2008. Elongation factor 2 and fragile $\mathrm{X}$ mental retardation protein control the dynamic translation of Arc/Arg3.1 essential for mGluR-LTD. Neuron 59: $70-83$.

Pautler RG. 2004. In vivo, trans-synaptic tract-tracing utilizing manganese-enhanced magnetic resonance imaging (MEMRI). NMR Biomed 17: 595-601.

Pautler RG, Silva AC, Koretsky AP. 1998. In vivo neuronal tract tracing using manganese-enhanced magnetic resonance imaging. Magn Reson Med 40: $740-748$.

Proud CG. 2000. Control of elongation phase of protein synthesis. In Translation control of gene expression (ed. N Sonenberg et al.), pp. 719-739. Cold Spring Harbor Laboratory Press, Cold Spring Harbor, NY.

Redpath NT, Proud CG. 1993. Cyclic AMP-dependent protein kinase phosphorylates rabbit reticulocyte elongation factor-2 kinase and induces calcium-independent activity. Biochem J 293: 31-34.

Richter JD, Klann E. 2009. Making synaptic plasticity and memory last: Mechanisms of translational regulation. Genes Dev 23: 1-11.

Rosenblum K. 2008. Conditioned taste aversion and taste learning: Molecular mechanisms. In Learning and memory: A comprehensive reference (ed. J Byrne), pp. 217-234. Elsevier Academic Press, Waltham, MA.

Rosenblum K, Meiri N, Dudai Y. 1993. Taste memory: The role of protein synthesis in gustatory cortex. Behav Neur Biol 59: 49-56.

Scheetz AJ, Nairn AC, Constantine-Paton M. 2000. NMDA receptor-mediated control of protein synthesis at developing synapses. Nat Neurosci 3: 211-216.

Serrano F, Deshazer M, Smith KD, Ananta JS, Wilson LJ, Pautler RG. 2008. Assessing transneuronal dysfunction utilizing manganese-enhanced MRI (MEMRI). Magn Reson Med 60: 169-175.

Silva AC, Bock NA. 2008. Manganese-enhanced MRI: An exceptional tool in translational neuroimaging. Schizophr Bull 34: 595-604.

Silva AC, Lee JH, Aoki I, Koretsky AP. 2004. Manganese-enhanced magnetic resonance imaging (MEMRI): Methodological and practical considerations. NMR Biomed 17: 532-543.

Smith EM, Proud CG. 2008. cdc2-cyclin B regulates eEF2 kinase activity in a cell cycle- and amino acid-dependent manner. EMBO J 27: $1005-1016$.

Sonenberg N, Hershey WB, Mathews MB. 2000. Translation control of gene expression. Cold Spring Harbor Laboratory Press, Cold Spring Harbor, NY.

Sutton M, Taylor A, Ito H, Pham A, Schuman E. 2007. Postsynaptic decoding of neural activity: eEF2 as a biochemical sensor coupling miniature synaptic transmission to local protein synthesis. Neuron 55: 648-661.

Verpelli C, Piccoli G, Zanchi A, Gardoni F, Huang K, Brambilla D, Di Luca M, Battaglioli E, Sala C. 2010. Synaptic activity controls dendritic spine morphology by modulating eEF2-dependent BDNF synthesis. J Neurosci 30: 5830-5842.

Weng JC, Chen JH, Yang PF, Tseng WY. 2007. Functional mapping of rat barrel activation following whisker stimulation using activity-induced manganese-dependent contrast. Neuroimage 36: 1179-1188.

Yamaguchi H, Matsushita M, Nairn AC, Kuriyan J. 2001. Crystal structure of the atypical protein kinase domain of a TRP channel with phosphotransferase activity. Mol Cell 7: 1047-1057.

Yu X, Nieman BJ, Sudarov A, Szulc KU, Abdollahian DJ, Bhatia N, Lalwani AK, Joyner AL, Turnbull DH. 2011. Morphological and functional midbrain phenotypes in Fibroblast Growth Factor 17 mutant mice detected by Mn-enhanced MRI. Neuroimage 56: $1251-1258$.

Received August 14, 2011; accepted in revised form January 5, 2012. 


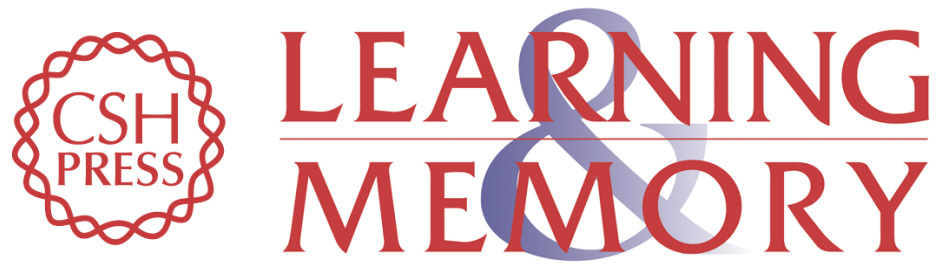

\section{Impaired associative taste learning and abnormal brain activation in kinase-defective eEF2K mice}

Iness Gildish, David Manor, Orit David, et al.

Learn. Mem. 2012, 19:

Access the most recent version at doi:10.1101/Im.023937.111

References This article cites 44 articles, 7 of which can be accessed free at:

http://learnmem.cshlp.org/content/19/3/116.full.html\#ref-list-1

License

Email Alerting Receive free email alerts when new articles cite this article - sign up in the box at the Service top right corner of the article or click here. 